\section{1. \\ COMETT Project: A Multimedia Teaching Instrument in the Field of Burns}

\section{Maesellis}

Department of Plastic Surgery and Burns Center of Host

Civico, Palermo, Italy and the Mediterranean Burns Club

A multimedia project is described for the training and updating of medical and paramedical staff working in burn care. The project, proposed by the $\mathrm{MBC}$ and sponsored by the EU, involves five Burns Centers (Athens, Barcelona, Toulouse, Turin, and Palermo) which belong to the same geographical area and are engaged daily in the treatment of burns.

The purpose of the project is to integrate the knowledge and experience of some Mediterranean countries in the field of burns pathology in order to build a common fund knowledge. More specifically, a multimedia self-teaching program has been developed on the following subjects: prevention, aetiology, phisiopathology, medical therapy in its general and nutritional aspects, surgical and topical therapy, functional recovery and psychology, fire disasters and their management. The program has been produced on CD-ROM because of the wide popularity of this system which as a result of its multimedia characteristics (simultaneous use of different types of media: sound, text, still and moving pictures) and interactivity is particularly suitable for teaching purposes. The interactive aspect means that there is continuous collaboration between the user and the computer which requires high levels of concentration. There is, therefore, the ideal one-to-one relationship between teacher and pupil, and this means a $40 \%$ learning gain compared to traditional courses. The impact of this product will guarantee permanent training of staff engaged in burns treatment especially in centers operating in the Mediterranean area.

\section{7.}

\section{How to Learn Decision-Making in Emergencies Mattila A.K. Matti}

Kuopio University Hospital, Kuopio, Finland

It is extremely important to perform emergency care in accidents and disasters in right priority order. The survival of victims is greatly dependent on the working tactics of the emergency teams at the scene. The success in rescue depends on the decisions of what to do, in which order, and who shall perform it with which equipment. The efficient utilization of transportation resources available is nearly as important in order to guarantee optimal survival of the causalities until they reach the hospital for intensive care and surgery. It is not easy to get or organize training for tactical decisions. Compared with technical training of emergency procedures, the probabilities for training in leading an emergency group, in making decisions, and in using of resources are negligible. There are needs for much more training for doctors, nurses, paramedics, and amateurs.

We have created a computer simulation software, Matimed, for training of tactics in accidents using a normal personal computer. The trainer is given the task of organizing emergency care and transportation in an accident on computer screen with members of a group and limited amounts of equipment. There are nine degrees of progressive difficulty in the form of increasing number of casualties.

Our three years of experience using this interactive training methodology have shown that there is an obvious need for training of correct tactics. The impression of this type of interactive training has been very favorable both for teacher and trainers. The software will be demonstrated.

\section{2.}

\section{Training for Disasters}

\author{
J.F. Navein, A.D. Redmond
}

U.K. Med Stoke, England

It is important that those employed to work in disasters are properly trained and have been adequately assessed to ensure competence. To this end the Society of Apothecaries of London has developed a Diploma in the Medical Care Catastrophes. As part of this initiative, UKMed and the University of Keele are developing and running two separate courses on disaster medicine. The first concentrates on practical skills, and the second on the theoretical aspects of disaster medicine. We are in the process of extending the scope of these courses by developing links with the Institute for Migration Studies in Geneva and the Uniformed Services University for the Health Sciences in Washington to establish a network of mutually recognized modules and examinations. We will cover the proposed content of these courses and develop the idea of an internationally recognized diploma to establish an individual's core knowledge, understanding, and competence in the important field of disaster medicine.

005.

\section{Emergency Care Training in the Computer Age}

Larry M. Strarr, PhD

Department of Psychology, Villanova University and the Department of Medical Education and Research, Oxygen

Therapy Institute, and SOS Technologies

In order to learn cardiopulmonary resuscitation (CPR) or first aid (FA), non-medical volunteers complete a standardized training class. The most well-known of the providers of training in the U.S. are the American Red Cross and the American Heart Association. However, other national organizations are available. The National Safety Council and SOS Technologies also have a network of offices and trainers, have created comparable education programs, and teach hundreds of thousands of people annually.

This paper will examine and compare the courses, underlying assumptions, use of audio-visual support materials, and other characteristics that are designed to bring those in the community to a level of competence and to respond to medical emergencies. 